\title{
VOLVER A LA TRADICIÓN: LATINE DISCERE IVVAT
}

\author{
ANTONIO G. AMADOR \\ IES Severo Ochoa (Granada) \\ agamador@gmail.com \\ ORCID: 0000-0002-6529-3137
}

\section{RESUMEN}

La intención del presente artículo es repasar brevemente la historia de la metodología empleada para la enseñanza del Latín y el Griego en nuestro país y otros estados europeos durante el siglo XX, haciendo hincapié en los diversos intentos de recuperar las bases de la tradición humanística y luchar contra el método de gramática-traducción, mal llamado "tradicional", implantado por la escuela prusiana en la segunda mitad del siglo XIX y destinado más a formar individuos a través de una "gimnasia mental" que a enseñar lenguas clásicas. En ese sentido, procuraremos demostrar cómo el uso activo en el aula de la lengua objeto de estudio por parte de profesores y alumnos, tanto de forma oral como escrita, es beneficioso no solo para el aprendizaje de dicha lengua, sino para un más profundo conocimiento de esta, convencidos de que trabajando la competencia lingüística, y no solo la teoría gramatical, conseguiremos devolver a nuestros estudios su importancia en el actual sistema educativo.

PALABRAS CLAVE: latín, griego, metodología, didáctica, humanismo, secundaria.

\section{RETURN TO TRADITION: LATINE DISCERE IVVAT}

\section{ABSTRACT}

The purpose of this paper is to briefly review the history of the methodology used to teach Latin and Greek in our country and other European states during the twentieth century. I will highlight the diverse attempts to recover the foundations of the humanistic tradition and struggle against the method of grammar-translation, misnamed 'traditional'. This method was set up by the Prussian school in the second half of the nineteenth century and conceived to train individuals through a 'mental gymnastics' more than to teach classical languages. In this sense, I will try to demonstrate how the active use of the target language in the classroom by teachers and students, both orally and in writing, is beneficial not only to learn that language, but to deepen the knowledge on it. I am convinced that practising linguistic competence, and not only teaching grammatical theory, can make our studies relevant again in the current educational system.

KEYWORDS: Latin, Greek, methodology, didactics, humanism, secondary education.

\section{INTRODUCCIÓN}

¿A qué tradición nos referimos cuando defendemos la vuelta a los métodos "tradicionales" para la enseñanza y aprendizaje de las lenguas clásicas? Intentaremos dar respuesta a esta pregunta a partir de la opinión de distintos autores que han tratado esta cuestión, sobre todo, desde principios del siglo XX hasta nuestros días. 
En su breve (y magnífica) historia de la lengua latina, El latín ha muerto, ¡viva el latín!, un verdadero best seller en 2007 en Alemania, traducido al castellano en 2012, el profesor Wilfried Stroh (2012: 354) toma partido directamente con estas palabras:

Es evidente que pocas personas querrán aprender latín según el método habitual de muchas instituciones, que lo convierte en una especie de álgebra superior o tal vez de química. Se busca el núcleo del predicado -osculatur (él besa)- y se pregunta entonces por la totalidad de la frase a través de los complementos necesarios (¿Quién besa? Catullus ¿A quién besa? Lesbiam) y de otros detalles (¿Dónde besa? ¿Por qué besa? ¿Con qué frecuencia besa?). De izquierda a derecha, de derecha a izquierda, se va montando una frase hasta que finalmente tiene sentido. Nunca habría logrado Catulo besar a Lesbia o leerle sus poemas si ella hubiese tenido que esforzarse tanto para entenderlo. ¿No deberíamos, por lo tanto, intentar que el latín se aprenda por el camino natural de la escucha, la comprensión y el habla?

En el Renacimiento, los humanistas no tenían que defender que el latín se aprendía hablando, ya que era la lengua vehicular de la enseñanza. ${ }^{1}$ Pero en épocas posteriores también era la opinión compartida por los más ilustres pedagogos, entre los que cabe destacar a Comenius (1592-1670), que la práctica de la conversación en latín por parte de los alumnos debía ser previa o simultánea al aprendizaje de la gramática latina.

Para recordar el papel fundamental de Comenius, autor del "método objetivo" (v. infra), que dio lugar a mediados del siglo XVII a la llamada "enseñanza intuitiva", ${ }^{2}$ nada mejor que leer lo que sobre este nos cuenta Pablo Latapí (1993: 150 y 153) en "El pensamiento educativo de Comenio":

El gran principio [del arte de la enseñanza] es que todo aprendizaje deriva de la naturaleza y debe ser conforme a ella, "sin golpes, sin rigor ni presiones". De este principio se derivan tres normas fundamentales:

1. Omnia gradatim: el aprendizaje debe ser gradual.

2. Autopsia, que significa que es el alumno el principal autor de su educación, y

3. Auto-praxis, o sea que el conocimiento debe ser aplicado siempre que sea posible.

[...] El "método objetivo", propuesto por Comenio, consiste en poner al alumno en contacto con los objetos o sus representaciones -a través de los más sentidos posiblespara que él experimente activamente con ellos. Implica estimular la observación, la descripción y comprensión, el análisis, la retención y la aplicación. Como auxilio didáctico, Comenio propuso -ejemplarmente en el Orbis Pictus- unir a la palabra y concepto la ilustración del objeto. A través de 150 imágenes, el alumno tiene ante los ojos piedras y metales, flores y frutos, actividades humanas y fenómenos de la naturaleza. El mostrar a la imaginación el objeto facilita que omnia sponte fluant, absit violentia rebus (fluya

${ }^{1}$ Los interesados en conocer los procedimientos empleados por los humanistas en la enseñanza del latín pueden consultar el interesantísimo artículo "Sal Musarum" de la profesora Sandra Ramos, de la Universidad de Cádiz (Ramos Maldonado 2016).

2 La enseñanza intuitiva es aquella que busca que un conocimiento se adquiera sin la necesidad de emplear un análisis o un razonamiento anterior. 
todo con naturalidad, no se violente nada) como reza el pie de grabado de la portada del Orbis. El papel del maestro es estimular y conducir el aprendizaje con esos apoyos.

Siguiendo con la lectura del libro de Stroh, este sostiene que a día de hoy existen muchos profesores en todo el mundo que, a pesar de las restricciones de los planes de estudio y de los libros de texto, practican el "método directo", aplicado ya a todas las lenguas modernas.

Los detractores de esta metodología objetarán, en primer lugar, que "el latín es una lengua muerta". Quienes hayan leído su libro, replica Stroh, sabrán que esta objeción no es correcta: el latín lleva dos mil años "muerto" y, sin embargo, se ha usado en cada época como si fuera una lengua viva: baste recordar a importantes personajes de la política, las artes, la filosofía y las ciencias, como Copérnico, Kepler, Galileo, Descartes, Newton, Leibniz, Bacon, Linneo, e incluso Carlos Marx (1835) durante sus años de estudiante. Vivo o muerto, el latín sigue siendo un idioma, no una disciplina matemática.

Quien reclama hoy en día una enseñanza viva del latín, concluye el autor, no está pidiendo, por suerte, nada nuevo. Durante las últimas décadas se ha hecho mucho por este objetivo: editar libros de texto más amenos y vivos, aplicar a la enseñanza los conocimientos adquiridos por la psicología, incluir música ${ }^{4}$ y teatro en clase y, sobre todo, hablar latín con entusiasmo. No debemos olvidar que longum iter est per praecepta, breve et efficax per exempla (Sen. epist. 6.5).

Joaquín Pascual Barea, catedrático de Filología Latina de la Universidad de Cádiz, llega a afirmar en el prólogo al libro de Stroh (2012: 16) lo siguiente:

\begin{abstract}
Una de las conclusiones de esta historia consiste en la necesidad de enseñar el latín con la metodología propia de cualquier lengua extranjera, y no como una lengua que sólo pudiera ser traducida y estudiada como materia teórica. El cultivo ininterrumpido del latín durante los últimos doce siglos, el que buena parte de los autores clásicos la aprendieran como segunda lengua, el que las lenguas extranjeras no siempre sean enseñadas por profesores nativos, y sobre todo los resultados obtenidos con esta metodología prueban que el hecho de que el latín deba ser aprendido en la escuela y no cuente con hablantes nativos no constituye un obstáculo insalvable para su aprendizaje como segunda lengua.
\end{abstract}

3 “El método directo es el más extendido de entre los llamados métodos naturales. Sus planteamientos se basan en los supuestos naturalistas del aprendizaje de una lengua, es decir, en la convicción de que el proceso de aprendizaje de una segunda lengua es similar al proceso de adquisición de la primera lengua" (CVC).

${ }^{4} \mathrm{~A}$ este respecto, véanse las grabaciones de poesía griega y romana con música renacentista a cargo de Eusebius Toth y el coro Tyrtarion en el canal de YouTube de la Accademia Vivarium Novum, <www.youtube.com/user/vivariumnovum> [consulta: 3 diciembre 2019], y los Carmina Latina de Alessandro Conti (Alexander Veronensis) sobre textos de los primeros capítulos de Familia Romana de Ørberg, <www.alexanderveronensis.com> [consulta: 3 diciembre 2019]. 


\section{LA FORMALE BILDUNG ALEMANA Y EL CASO DE ITALIA}

Por su parte, Luigi Miraglia, en el capítulo "La enseñanza del latín a lo largo de los siglos" de su manual para el profesorado Nova Via, afirma que, cuando nos preguntamos cuál es el "método tradicional" para enseñar el latín y el griego, muchos no dudarían en responder: morfología, sintaxis, traducciones de frases y pasajes de autores. No obstante, el método gramática-traducción (también llamado "método prusiano" por su lugar de origen), ${ }^{5}$ contrariamente a la opinión común, es de introducción bastante reciente en la didáctica de las lenguas clásicas y no se remonta más allá del siglo XIX. Es hijo de varios factores que actuaron al mismo tiempo (Miraglia 2013: 9):

1. La denominada Formale Bildung (o "educación formal"), dirigida fundamentalmente a ejercitar una "gimnasia mental", y a desarrollar paciencia, atención, diligencia y "lógica", cualidades que después tendrían que transferirse al estudio de otros campos del saber, y constituir así una "formación de base" del carácter y de la actitud hacia el trabajo intelectual [...].

2. La influencia de la Ilustración primero y del Positivismo después, encaminados a investigar, también en la enseñanza de las lenguas clásicas, un "método científico" sistemático y racional.

3. El fuerte peso que tendrían las investigaciones de lingüística histórica, las sistematizaciones gramaticales, los estudios sobre sintaxis compleja y los avances de la filología clásica que caracterizaron a estas disciplinas, especialmente en el ámbito germánico.

4. La voluntad, no exenta de contenidos ideológicos, de proponer un método alternativo y "nuevo" al sistema de enseñanza que daba la impresión de ser un atributo exclusivo de instituciones eclesiásticas y de órdenes religiosas, y que parecía -habiendo en ello una parte de razón- privilegiar la forma sobre los contenidos, creando oradores y versistas privados de sentido común y de contacto con la realidad presente y viva.

El problema fue que nunca se llegaron a alcanzar los efectos que se esperaban de la aplicación del nuevo "método prusiano". Así, en Inglaterra y en Italia, relevantes intelectuales empiezan a protestar. Niccolò Tommaseo (1802-1874) llega a decir (Miraglia 2013: 10):

¿Por qué sufren tanto los jovencitos al aprender aquella lengua, ellos que, en cambio, aprenden de forma cómoda y rápida varias lenguas vivas? ¿Por qué aquella lengua

5 “El método gramática-traducción basa la enseñanza de una segunda lengua en el análisis detallado de las reglas gramaticales y sus excepciones para luego aplicar los conocimientos adquiridos a la traducción de oraciones y textos que se efectúa de la lengua meta a la propia y a la inversa. La primera lengua sirve como sistema de referencia en la adquisición de la segunda lengua.

Este método surgió en Prusia a finales del siglo XVIII y adoptó como modelo el sistema utilizado para la enseñanza del latín y del griego. Es heredero de la práctica académica alemana y algunos de sus representantes fueron J. Seidenstücker, K. Plötz, H. S. Ollendor y J. Meidinger.

[...] Durante la segunda mitad del siglo XIX se desarrolló en varios países europeos una corriente de oposición a este método que sentó las bases para el desarrollo de nuevas propuestas en la enseñanza de lenguas: el Movimiento de reforma" (CVC). 
permanece muerta en sus pensamientos? ¿Por qué, fuera de la escuela y de las tareas, la apartan de ellos como una molesta carga? Sería más importante oír hablar constantemente latín y tener que responder media hora al día que estudiar su gramática durante siete años.

Vistos los desastrosos resultados de esta metodología, en 1905 se convoca una comisión en Italia para analizar la situación de la enseñanza del latín, que concluye (Miraglia 1996: 1) que

el método adoptado en las escuelas italianas para la enseñanza de las lenguas clásicas es el más dificultoso y el menos rentable; es poco útil para el conocimiento de la lengua y aún menos para el conocimiento del espíritu literario.

En su informe, los miembros de la comisión identificaban el fracaso en dos errores de fondo (Miraglia 1996: 1):

El primero, el más grave y más frecuente y, además, aquel del que a menudo más quejas se tiene, es el de comenzar inmediatamente por una enseñanza sistemática de la gramática para introducir el conocimiento de la lengua, y después seguir insistiendo en ello, como si en el aprendizaje de sus reglas y en los repetidos ejercicios para aplicarlas consistiese toda razón de estudio de una lengua, incluso la esencia de la misma. El otro error, también frecuente pero menos generalizado, consiste en extender, más allá de los conocimientos y necesidades propias de la escuela secundaria, la erudición filológica y el análisis gramatical, morfológico y sintáctico de la palabra, de la frase y del período, de modo que la palabra per se se convierte en el objetivo principal de la enseñanza de la lengua.

Finalmente, en el Congreso sobre la didáctica de las lenguas clásicas en los países de la CEE, celebrado en 1963, se llegó a la conclusión unánime (Miraglia 1996: 1) de que

el joven estudiante de latín se enfrenta a análisis y abstracciones superiores a los de su propia lengua materna. En estos estudios se desarrolla todo, como si la psicología moderna y la pedagogía experimental no existieran todavía.

Pero no había nada que hacer, los profesores se sentían satisfechos, aunque los alumnos no aprendían mucho: el mito de la "formación mental" les bastaba para tranquilizarlos. El mejor ejemplo lo podemos encontrar en un manual de 1947, Latinorum, de Michele Fornaciari, que gozó de tanta popularidad que en seguida fue traducido al castellano y editado en nuestro país. Curiosamente, Fornaciari (1952: 67) parecía añorar los antiguos métodos empleados por los "colegios religiosos", llegando a elogiar sus resultados:

La posibilidad de hacer aprender el latín prácticamente, parece ser confirmada por lo que todos hemos oído contar a ciertos viejos estudiosos, acerca de la manera de como lo habían aprendido, en sus tiempos, en las Escuelas Pías, o en otros colegios de religiosos. Según ellos, los Barnabitas y los Escolapios usaban un método que descartaba todas las molestias gramaticales; el muchacho era introducido en seguida en el prado verde y 
agradable de la historia y de la poesía, y el latín era enseñado al igual que una lengua viva, como el alemán o el francés. Y a menudo, además, criticaban el método nuevo "inventado por los filólogos alemanes", en virtud del cual la enseñanza del latín había quedado privada, podríamos decir, de sus hojas y de sus flores, y convertida en una selva espinosa y erizada de reglas gramaticales y de sintaxis.

El propio autor (Fornaciari 1952: 69-70) se atreve a criticar incluso que, con el cambio de metodología, la enseñanza se ha endurecido por el exceso de celo de determinados profesores:

Pero en las escuelas públicas se verificó un hecho nuevo. Todos los profesores, entonces jóvenes y "modernos", se hallaban más o menos influidos por la escuela filológica alemana, dominadora del siglo. Y de aquella no solamente aprendieron, y por cierto muy bien, las leyes de las variaciones morfológicas y sintácticas del latín, sino que dedujeron también la tendencia a endurecer demasiado el método de enseñanza y a exagerar un poco el carácter científico de la enseñanza misma.

[...] Encontramos a profesores muy preparados, pero demasiado propensos a explicarnos todos los porqués fonéticos de la desaparición y de las elisiones de las consonantes en las declinaciones latinas y demasiado convencidos de que "el latín de los curas" -es decir, el latín de los colegios privados- no era enseñado con un método filológicamente al día. [...] En conclusión, aquellos maestros estaban persuadidos de que la ventaja esencial del latín consiste en su capacidad de formar el cerebro del muchacho, y en esto tenían razón; pero estaban demasiado seguros de ello, y pretendían que nuestro cerebro funcionara como el de filólogos en ciernes.

$\mathrm{Y}$ entonces, pese a que todas estas afirmaciones fueran ciertas, argumenta en contra de aquella enseñanza por no considerarla lo suficientemente "seria" (Fornaciari 1952: 71):

Cierto es que se podría enseñar el latín prácticamente, como cualquier otro idioma. Nada impediría que se hicieran ejercicios de nomenclatura latina, enseñando a los muchachos en primer lugar cómo se dice papel, pluma, tinta y tintero, y haciéndoles soltar la lengua con pequeñas frases, para ponerlos en condición de sostener lo antes posible una conversación en latinus grossus...

Pero con tal enseñanza no se llegaría a un resultado serio. En realidad, no pretendemos enseñar el latín a los muchachos con el fin de que se sirvan de él para conversar o para escribir cartas comerciales, sino para otro objeto. Queremos enseñárselo para encaminarles a ser hombres cultos, para hacer funcionar puntualmente su capacidad de raciocinio y para que vislumbren algo de la civilización clásica. Resulta pues claro que, en relación con ese fin, llegar a balbucear alguna frase, no sería gran cosa. Y además, el mismo muchacho que aprendiera de tal forma el latín, con un manual de conversación en la mano, comprendería que se trata de un simple juego y no lo tomaría en serio.

La afirmación de Fornaciari de que el latín se ha de enseñar para hacer funcionar la capacidad de raciocinio de los muchachos constituye una verdadera losa que ha acompañado al estudio de esta lengua durante casi un siglo y de la que, aún hoy, no nos hemos librado del todo. El autor nos viene a decir, por tanto, que lo importante del estudio del latín no es el latín mismo, algo totalmente inimaginable si se dijera de cualquier otra lengua o materia de 
estudio. La conclusión es aún peor: el sentido que pueda tener el texto no tiene la menor importancia ante el mero ejercicio mental que proporciona el estudio de la lengua del Lacio (Fornaciari 1952: 72):

Es inútil, por lo tanto, buscar atajos en el estudio del latín y proponerse ingenuamente estudiarlo con los mismos recursos que pueden ser eficaces para los otros idiomas. El latín, para ser verdaderamente útil, no puede estudiarse más que con un método: el de la enseñanza gradual y teórica de la gramática y la sintaxis, aplicándola luego en las traducciones del latín a la lengua propia y, sobre todo, de ésta al latín.

Finalmente, sentencia que el error de los que preguntan por qué el latín no se enseña de una manera práctica es que no conocen el verdadero propósito de su estudio por parte de los jóvenes, llegando a la más absurda de sus afirmaciones: "no se dan cuenta de que el fin del estudio del latín no es comprender el sentido de un párrafo latino, sino razonar sobre el latín y construir el latín por dicho método razonador" (Fornaciari 1952: 101).

De poco le sirvió unos años más tarde a Gaetano Righi, en su Historia de la filología clásica, escrita en 1962, argumentar contra la inerte erudición de los profesores y el estorbo preliminar de la gramática. El avance del método prusiano era imparable (Righi 1969: 38):

La mucha erudición no aumenta, de suyo, el vigor del espíritu, no suministra ni la elocuencia, ni el gusto, ni el amor que incitan a explicar los autores [...]; la erudición no establece de por si el vínculo entre el pasado y el presente; no justifica ni promueve mi interés por la remota Antigüedad, por los hombres que vivieron y escribieron entonces y representan aun a aquellos tiempos en los libros que se han conservado y que son sus exponentes. A estos, a los escritores y poetas, hay que explicarlos; o sea, hay que interpretarlos, hacerles hablar elevándonos nosotros a sus pensamientos y sentimientos, los cuales al mismo tiempo nos harán entendernos a nosotros en ellos y harán que les entendamos a ellos en nosotros. Naturalmente, para conseguir esto es preciso haber superado todo estorbo preliminar de gramática y sintaxis e inerte erudición y fijarse ya lo más posible en su puro lenguaje, en su rostro vivo. Pero lo que suele suceder, por el contrario, es que durante todos los años que se estudia latín y griego en la enseñanza secundaria no se supera el referido estorbo.

\section{EL CASO DE ESPAÑA}

En nuestro país, mientras tanto, a pesar de los encomiables esfuerzos de los redactores de Palaestra Latina, ${ }^{6}$ una revista escrita enteramente en latín fundada en 1930 por el claretiano Manuel Jové y dirigida más tarde por José María Mir, ${ }^{7}$

${ }^{6}$ Gracias a un fructífero acuerdo de colaboración entre la Asociación Cultura Clásica y la Orden de los Claretianos, la mayor parte de los números publicados entre 1930 y 1975, fecha de su cierre definitivo, pueden consultarse en $<w w w . c u l t u r a c l a s i c a . c o m / p a l a e s t r a l a t i n a>$ [consulta: 4 diciembre 2019].

7 Redactor de Candidatus Latinus y de Palaestra Latina, el padre Mir (1912-2000) asumió la dirección de esta revista desde 1943 hasta 1964. Participó activamente en el Movimiento por el Latín Vivo y dirigió la redacción del curso de latín en discos Polyglophone CCC (San Sebastián, 
el método gramática-traducción no tarda en imponerse en las aulas, tanto en la enseñanza secundaria como en la superior.

Contra los efectos provocados por este avance imparable, se alzarán voces como la de J. Jiménez Delgado (1909-1989), profesor de la Universidad Pontificia de Salamanca, que, entre otros artículos, publica en 1959 “El Latín y su didáctica", defendiendo una revisión de la metodología del latín ante los ataques contra la permanencia de este en el sistema educativo (Jiménez Delgado 1959: 153-154):

Los ataques contra el latín se han agudizado en estos últimos años. No nos interesa, de momento, entrar en la razón o sin razón de estos ataques. Nos basta con dejar constancia del hecho y luego tratar de contrarrestarlos más con realidades que con palabras.

Tal vez el argumento más fuerte que lanzan los impugnadores del latín es la ineficacia y casi esterilidad de su enseñanza. [...]

Si queremos dar eficacia a la didáctica del latín urge revisar, actualizar y vivificar su metodología. Todas las disciplinas han renovado sus métodos, incluso las lenguas vivas. ¿Por qué habrá maestros que se empeñen en seguir con procedimientos anticuados, sobre todo teniendo en cuenta la disminución en el horario de clases y el desinterés de la sociedad actual y de los mismos alumnos por el latín? [...] La batalla planteada en torno al latín no la ganaremos con discursos ni apologías más o menos contundentes. Hay algo mejor que la propaganda verbal o escrita: la calidad y el provecho de nuestros alumnos.

[...] Urge, pues, una renovación profunda en la enseñanza del latín, a base de métodos más modernos, pero sin perder el espíritu que inspiró a los grandes maestros del Renacimiento y que les permitió llegar a un dominio tal de esta lengua sabia, que aún hoy día causa general admiración. No hay motivo para seguir enseñando el latín como lengua muerta, ni menos para continuar con una didáctica que sólo engendra en los alumnos el tedio y la repulsa de la asignatura. [...] Esto, unido a un uso discreto y sabio de la gramática, a la necesidad de hacer desde los primeros años un buen acopio del vocabulario y orientar en lo referente a la traducción, sin descuidar el ejercicio de hablar $y$, sobre todo, de escribir latín, de tan frecuente uso en otros tiempos y de resultados tan maravillosos si se hace como es debido, no podrá menos de darnos excelentes frutos.

Concluye su artículo con los votos de carácter pedagógico formulados en el Congreso Internacional en pro del Latín Vivo celebrado en Aviñón en septiembre de 1956 (Jiménez Delgado 1959: 170-171):

I. La pedagogía del latín no debe estar influida por la idea de que el latín es una lengua muerta.

II. Debe hacerse campaña recalcando la idea de que el latín es no sólo un factor cultural, sino también una lengua de interés práctico.

III. Hay que esforzarse en hacer la enseñanza del latín más atrayente y más adaptada a la psicología de los niños, sin caer, con todo, en el engaño de una facilitonería contraproducente. [...]

1959). Colaboró en la revista Helmantica y remodeló en equipo el Diccionario ilustrado latinoespañol, español-latino Vox (1944), que ha alcanzado numerosas reediciones y sigue siendo el léxico escolar de referencia en nuestros institutos. 
IV. Se hace una llamada a los profesores para que procuren facilitar a los alumnos un vocabulario no escaso para sus tareas escolares y para las contingencias del día de mañana, usando en esto los métodos más acreditados.

V. Se recomienda el empleo de métodos activos en la enseñanza del latín.

VI. Es muy conveniente que los maestros de lengua y literatura latina intensifiquen el uso del latín por escrito y de palabra.

VII. Además de los autores clásicos, es de desear que se empleen también textos recreativos sacados tanto de la Antigüedad como de la Edad Media y Moderna, arreglados, si es preciso, en lenguaje sencillo, correcto y elegante.

Para Jiménez Delgado (1959: 168), por tanto, uno de los secretos para el triunfo de la restauración de la enseñanza del latín era la consigna que el profesor Burk proclamaba solemnemente en el citado Congreso de Aviñón: Latine loqui, latine loqui, iterum iterumque latine loqui. Algo muy en la línea de lo propuesto por Comenio (1657: 129) en el siglo XVII: omnis lingua usu potius discatur quam praeceptis, id est, audiendo, legendo, relegendo, transcribendo, imitationem manu et lingua tentando quam creberrime.

Tampoco tuvo éxito en nuestro país esta arenga a la cordura de Jiménez Delgado, pues dos décadas después del Congreso de Aviñón, en 1976, y ya extinto el antiguo bachillerato, la propia SEEC publica el libro de latín de $2^{\circ}$ de BUP de Francisco Torrent en cuyo prólogo (1976: 5) se afirma lo siguiente:

La asignatura cuyo estudio vamos a comenzar tiene mucho de pasatiempo: en ella, como en un rompecabezas, es necesario encajar debidamente las piezas que se nos dan en los textos, de acuerdo con su forma y con el papel que desempeñan en el conjunto. Y es, al mismo tiempo, apasionante, porque su estudio nos va a proporcionar los conocimientos y la técnica necesarios para que el ajuste de piezas sea correcto y nos permita descifrar, a veinte siglos de distancia, unos textos llenos de interés humano, de belleza difícilmente igualable y de importantes lecciones, que dejaron escritos nuestros antepasados, los romanos.

La técnica se irá adquiriendo y perfeccionando a lo largo del curso mediante la práctica de la traducción. [...] Lo que sí será indispensable es repasar concienzudamente algunas nociones fundamentales de Gramática, que ya se estudiaron con anterioridad, y que conviene tener muy presentes, porque habrá que recurrir a ellas constantemente en el aprendizaje del Latín y en el ejercicio de la traducción. Sólo así pisaremos terreno firme y lograremos en nuestra asignatura la eficacia deseada.

\section{FRANCIA Y LOS MÉTODOS AUDIO ORALES}

En 1974 Jacqueline Duchemin, profesora de la Universidad de París X Nanterre, preocupada por la deriva de los estudios clásicos en Francia, escribe el prefacio a la obra de Janine Debut, La enseñanza de las lenguas clásicas, en la que se hace hincapié en la necesidad de una renovación de la metodología del latín y el griego (Debut 1976: 6-7):

Desde hace mucho tiempo, a decir verdad desde siempre, los maestros dignos de este nombre han contemplado con mirada crítica e inquisitiva los métodos y los instrumentos de trabajo recibidos de sus predecesores. Semejante en eso a los técnicos e ingenieros que 
renuevan sin cesar el utillaje para fabricar más y mejor, los maestros modernizan el material pedagógico y los métodos de enseñanza.

[...] [Janine Debut] ha utilizado los medios más modernos de que se dispone hoy, a pesar de la opinión en contra de muchos que estiman, equivocadamente, que los mismos deben reservarse al estudio de las lenguas modernas.

El principal problema, apunta Debut, es que el latín ya no constituye una lengua para nuestros alumnos, sino una materia que les proporciona deberes escolares. Conviene, por tanto, situar la pedagogía de las lenguas clásicas en el interior de las llamadas secundarias, es decir, de las distintas a la lengua materna. Siguiendo a Sebastianoff, profesor de la Sorbona, afirma que cualquier lengua funciona esencialmente como medio de comunicación y que, por tanto, conocer una lengua consiste en ser capaz de comprenderla y de expresarse en ella.

Partiendo de esta idea, defiende el método vivo argumentando que su finalidad no estriba en enseñar las lenguas clásicas como si fueran a ser utilizadas igual que una lengua viva, sino en habituar a los alumnos, mediante frecuentes diálogos en latín o en griego, "a retener en la memoria un conjunto sintético de la frase, más que la frase aislada, equipada de su traducción" (Debut 1976: 58). Para la autora, si se les llama métodos activos no es porque ejerciten los músculos, sino porque obligan al alumno a un esfuerzo sostenido de atención, de reflexión metódica. Así, en el capítulo "Los métodos dinámicos", cita la opinión de varios profesores (Debut 1976: 56):

No hay nada que despierte tanto el interés de los alumnos como los ejercicios orales de todas clases: pequeñas órdenes y preguntas simples [...]. Se puede bromear acerca del valor formativo del procedimiento consistente en decir en latín al alumno: "Cierra la puerta, regresa a tu puesto o ven a la pizarra". Esto carece de relación, es cierto, con el humanismo, pero ¿quién negará el valor pedagógico de la repetición? ¿No es el mejor ejemplo aquel que se puede utilizar más frecuentemente? Y ¿cuántas veces por semana no hay ocasión de repetir: "Labōrāte, nē rīseritis! Audīte! Cōgitā, antequam respondeās..."? ¿Cuántos niños creéis capaces de recordar de memoria una lista de números cardinales y sobre todo ordinales, si dicha tarea no les es facilitada? Pero cuando uno se atiene, desde principio de curso, a dar en latín las indicaciones de trabajo, es sorprendente comprobar lo poco que se equivocan, al cabo de unas semanas, acerca del número de un ejercicio: "Librōs sūmite! Opus ducentēsimum quaerite, in pāginā centēsimā trīcēsimā quīntā!"'.

Con respecto al uso del diccionario, Debut (1976: 70) opina que los alumnos pasan un tiempo precioso entregados a hojearlo, tiempo que les convendría mucho más dedicar a la reflexión sobre el texto, y se muestra de acuerdo con las palabras de Duchemin:

Anonadado, aturdido, el desgraciado si es consciente pasará la velada haciendo verdaderas filigranas con todas las combinaciones posibles, en una progresión verdaderamente aterradora, que ni siquiera me atrevo a calcular... Es muy raro, en tales condiciones, que llegue a alcanzar un significado un poco parecido, mucho más raro que descubra y alcance el sentido justo. 
De tal modo que nuestra autora llega a afirmar que el uso abusivo del diccionario es una de las principales causas del declive de la enseñanza del latín y el griego, por lo que propone reducir al máximo su utilización (Debut 1976: 85):

¿Qué es si no, en efecto, la mayor parte de las veces, un texto griego o latino, para
nuestros alumnos? Una especie de criptograma para ser descifrado; la clave, el
diccionario la dará. No destacaremos nunca bastante los daños que causa el diccionario
con el cual imaginan traducir un texto. La explicación es de orden psicológico: los
alumnos no retienen el vocabulario por falta de motivación, puesto que cuentan con el
diccionario.

Por lo que coincide con Duchemin en que hay que erradicar prácticamente su uso para salvar la enseñanza del latín y el griego, gravemente dañada por esta causa (Debut 1976: 71):

Nos resulta forzoso reconocer que todos hemos propinado un duro golpe al latín y al griego, convirtiéndolas en lenguas para las que se precisa, en primer lugar, el diccionario, y este abuso parece ser el principal responsable del decaimiento de las lenguas clásicas. $\mathrm{Si}$ después de haber estudiado las lenguas clásicas durante cinco o seis años los alumnos ignoran las palabras corrientes, significa que el latín y el griego, lo queramos o no, y a pesar de los esfuerzos que hagamos entre todos, son lenguas muertas.

Finalmente, sostiene que "la práctica oral del griego y el latín, basada en preguntas y respuestas sugeridas por el texto, parece en sí un acercamiento vivo de la lengua", llegando a la conclusión de que hay que replantearse la pedagogía del latín, ya que es absurdo privarlo de esos poderosos factores de aprendizaje que son la audición y la charla: "el uno precisa la movilización rápida del vocabulario y las estructuras para expresar un pensamiento; el otro, una comprensión global para entregarse al pensamiento del interlocutor". En conclusión, "la gramática puede difícilmente servir de medio de acceso a la lengua real, en la que el reflejo debe superar a la reflexión” (Debut 1976: 100).

\section{LA REACCIÓN BRITÁNICA}

Todos estos movimientos, que tuvieron mejor o peor suerte en los distintos sistemas educativos europeos, estaban influenciados por la reforma de los estudios clásicos que se había iniciado en Inglaterra a principios del siglo $\mathrm{XX}$ como reacción al gramaticalismo de la Formale Bildung. Así, en Cambridge, W. H. D. Rouse (1863-1950), fundador de la Loeb Classical Library, deja la Universidad preocupado por el bajísimo nivel de los alumnos que se matriculan en las distintas Filologías y escribe lo siguiente:

El método actualmente en uso no se remonta más allá del siglo XIX. Es fruto de la erudición alemana, que intenta aprender todo respecto a una cosa en vez de la cosa en sí 
misma. El método tradicional inglés, que duró mucho más allá del siglo XVIII, era usar la lengua latina hablándola. ${ }^{8}$

Rouse asume la dirección de la Perse School y, en breve, se unen al proyecto Appleton, Jones, Paine, Mainwaring, Andrew, Arnold y otros jóvenes profesores. Escriben numerosos libros sobre la didáctica de las lenguas clásicas aplicando lo que denominan el "método directo" y consiguen enseñar con excelentes resultados que sorprenden a todo el mundo. El método se extiende por distintas escuelas de Inglaterra y por fin llega a Estados Unidos, donde se difunde con éxito. Rouse funda la Association for the reform of Latin teaching y, desde 1911, dirige un centro de formación del profesorado, las Schools of Latin teaching, y edita la revista Latin teaching.

Consciente del cambio de rumbo que estaba propiciando, Rouse escribe en el prólogo a Decem fabulae, un libro de obritas de teatro en latín escrito por Paine y Mainwaring:

\begin{abstract}
Afortunadamente, ya no es necesario defender el método directo en la enseñanza de idiomas: nadie cuya opinión se base en el conocimiento lo ataca hoy en día, siempre que los idiomas que se impartan sean modernos. Pero hubo un tiempo, no hace mucho, en el que el método fue ridiculizado como simple o descuidado por los que no lo habían probado; y este es el caso ahora con el método directo aplicado a la enseñanza del latín y el griego. Los que lo han intentado, hasta donde llega mi conocimiento, lo tienen bastante claro: lo han encontrado no sólo más rápido y más atractivo, sino que consigue sin duda lo que el método pretende, es decir, que mantiene la atención en los detalles, la mente despierta, y permite a los estudiantes entender y apreciar las mejores cualidades de la mejor literatura. ${ }^{9}$
\end{abstract}

Una reflexión bastante moderna, para haber sido escrita hace más de un siglo, en mayo de 1912.

En mitad del proceso de renovación de la enseñanza de las lenguas clásicas, el estallido de la Primera Guerra Mundial provocó la muerte de algunos de los más estrechos colaboradores de Rouse. Esto, sumado a los celos que suscitaba su éxito, además de la resistencia de las escuelas públicas a la experimentación, sobre todo por el esfuerzo añadido que suponía para muchos

8 "The current method is not older than the nineteenth century. It is the offspring of German scholarship, which seeks to learn everything about something rather than the thing itself: the traditional English method, which lasted well beyond the eighteenth century, was to use the Latin language in speech" (Rouse y Appleton 1925: 2).

9 "It is fortunately no longer needful to defend the Direct Method of teaching languages: no one whose opinion is based on knowledge now attacks it, so long as the languages to be taught are modern. But there was a time, not so long ago, when the method was derided as foolish or slovenly by those who had not tried it; and this is the case now with the Direct Method of teaching Latin and Greek. Those who had tried it, far as my knowledge goes, are quite as ease in their minds: they have found not only that it is quicker and more attractive, but that it does really what the exercise-book method pretends to do, that is, it holds the attention in detail, the mental faculties, and enables the scholars to understand and to appreciate the best qualities in the best literature" (Paine et al. 1912: 3). 
profesores trabajar con el "método directo", hicieron que la labor de Rouse se fuera debilitando paulatinamente. Tras su muerte, en 1950, a la misma asociación por él constituida se le dio otro nombre menos beligerante, Association for Latin teaching, y se dejó de hablar de reformas. Sin embargo, la herencia de Rouse no se perdió por completo: dos estudiosos provenientes de su escuela, Peckett y Munday, continuaron proponiendo el "método directo" en la enseñanza del latín y del griego y, aunque con cambios sustanciales, los denominados reading methods constituyen también el fruto de su esfuerzo de replanteamiento de la didáctica de las lenguas clásicas en Europa.

En nuestro país, en cambio, el alejamiento de los postulados anglosajones dará lugar a una contradicción más que evidente: mientras que en Estados Unidos o Inglaterra los profesores universitarios dirigían parte de sus esfuerzos a la creación de métodos atractivos e interesantes para el alumnado adolescente siguiendo la estela de Rouse (buen ejemplo de ello -por citar los más conocidos- son Ecce Rōmānī, los métodos de latín de Oxford y Cambridge, o $A \theta \eta ́ v \alpha \zeta \varepsilon$ para la lengua griega, editado por Oxford University Press), el mundo universitario español se centrará fundamentalmente en el aspecto más puramente filológico con dos vertientes básicas, además de la investigación propia de su campo: la publicación de gramáticas, traducciones y textos bilingües, que encontrarán su más conocido exponente en la creación de la editorial Gredos en 1944, y la clara orientación hacia la difusión de los estudios de filología germana en torno al mundo clásico.

\section{6. ØRBERG Y EL MÉTODO DIRECTO}

Debemos detenernos ahora en la figura de Hans H. Ørberg (1920-2010), que recoge lo que él mismo denomina el "gran experimento" de Rouse y su escuela, mejorando el método al prestar una mayor atención a la gradación de los textos y de la morfosintaxis, así como a la frecuencia del vocabulario. Es digna de destacar la meticulosidad con la que explica los distintos fenómenos gramaticales y los pone en práctica tanto en el texto como en los ejercicios posteriores.

\footnotetext{
Un joven estudioso danés, Hans Henning Ørberg, especialista en glotodidáctica y latinista, propone al Nature method Institute de Copenhague, entonces dirigido por Arthur Jensen, aplicar el "método natural"10 también al latín. Durante varios años trabaja intensamente en el proyecto, valiéndose de léxicos de frecuencia, del existente en el Thesaurus, y del corpus completo de los autores clásicos. Pesa con la balanza cada parte de su curso, dándole una estructura muy racional: primero la morfosintaxis nominal (nombres, adjetivos, pronombres) y después la verbal y del período y, como nexo entre
}

10 "El método natural basa sus planteamientos en la convicción de que el proceso de aprendizaje de una segunda lengua es similar al proceso de adquisición de la primera lengua. Este método es producto de los principios basados en esos supuestos naturalistas del aprendizaje de una lengua y de las propuestas del Movimiento de reforma de finales del siglo XIX" (CVC). 
las dos, un capítulo sobre el participio. Todo el vocabulario de la primera parte se estudia para que el alumno aprenda las palabras más frecuentes en los textos de autor. La inmersión en la lengua es total y el latín se explica con el latín, la lingua Latina es per sē illūstrāta. Una historia sin interrupción que engancha y cautiva, las nuevas formas y las nuevas estructuras poco a poco introducidas y repetidas con insistencia en varios contextos, las nuevas palabras insertas entre las ya aprendidas en una medida nunca superior al veinte por ciento y explicadas con sinónimos ya conocidos, circunlocuciones, antónimos, derivados e imágenes: en treinta y cinco capítulos se conduce al alumno desde la ignorancia total del latín al conocimiento de toda la morfología y de toda la sintaxis. Podrá después pasar progresivamente a la lectura de los autores, perfeccionando sus conocimientos gramaticales y ampliando de forma gradual el vocabulario. Los ejercicios no son de traducción, sino de completar espacios o de uso activo de la lengua. ${ }^{11}$

Desde 1954 hasta su muerte, en 2010, fue perfeccionando cada vez más su obra, que se convirtió así en uno de los textos para el aprendizaje del latín más extendido y eficaz en todo el mundo.

El curso Lingua Latina per se illustrata consiste en un método de aprendizaje inductivo-contextual ${ }^{12}$ que invita al estudiante a encontrar el significado de las palabras y de las expresiones en el contexto y en las ilustraciones. La lengua de comunicación para aprender el latín es el propio latín: del latín sencillísimo de los primeros capítulos del curso Familia Romana (Ørberg 1991) al refinado de los clásicos, que constituyen el grueso del segundo volumen, Roma aeterna (Ørberg 1990). La primera parte del curso presenta hechos y escenas de la vida de una familia romana del siglo II d. C., la segunda parte lleva al alumno a leer correctamente textos originales de Virgilio, Livio, Eutropio, Aulo Gelio, Nepote, Salustio, Cicerón y Horacio.

El aprendizaje del léxico es uno de los aspectos esenciales del curso. El vocabulario, basado en un léxico básico de frecuencia, con 1.500 palabras en el primer volumen y 2.500 en el segundo, es adquirido gradual y directamente, por medio de la sucesiva lectura de los textos con el apoyo de imágenes que facilitan la comprensión y favorecen la memorización del vocabulario, definiendo claramente los objetos e ilustrando varios aspectos de la vida romana.

La gramática no se desdeña en absoluto, pues cada unidad didáctica comprende una sesión de profundización gramatical del texto recién estudiado.

${ }^{11}$ Miraglia 2013: 18.

12 El método inductivo-contextual es un método de aprendizaje de lenguas desarrollado por Ørberg a partir del método directo. En él, "el alumno se aproxima a un aprendizaje graduado en el que es capaz de asimilar la nueva información, debido a que dispone implícita la teoría del input comprensible de Krashen (I+1), característica que diferencia a este método para el estudio del latín del resto de los que se engloban bajo el principio de los métodos naturales. Los alumnos consiguen descubrir el significado de las palabras y, por tanto, el argumento de la historia por medio del contexto, lo que parte de un aprendizaje inductivo también de las reglas gramaticales. El cambio fundamental establecido por este método es la focalización en la comprensión del texto en lugar de la gramática y la traducción, lo que genera una mayor confianza en el alumnado que se puede percibir, a priori, como más capacitado para adentrarse en el estudio de los textos clásicos" (López de Lerma 2015: 76). 
Morfología y sintaxis se presentan inductivamente, después se fijan sistemáticamente con una descripción explícita en el apartado final Grammatica Latina.

El propósito del curso no es otro que capacitar a los alumnos para que puedan leer y comprender los clásicos latinos. El curso se inserta, por tanto, en la línea de la tradición pedagógica iniciada en el siglo XVI por Erasmo, Vives y Clenardo, continuada en el XVII por Comenio con su Orbis sensualium pictus y recuperada por Rouse y su escuela a principios del siglo XX.

\section{LA REVOLUCIÓN SILENCIOSA}

Son muchos los profesores españoles que se han manifestado desde principios de este siglo, a través de artículos en la red y en revistas especializadas, a favor del cambio metodológico en la enseñanza y aprendizaje de las lenguas clásicas. En este sentido, es recomendable leer, entre otros, los artículos de Alfonso Alcalde-Diosdado (2000), Sandra Ramos Maldonado (2015), Cristóbal Macías Villalobos (2017), Jorge Tárrega (2018), Emilio Canales y Antonio G. Amador (2014). Por su parte, Carlos Martínez Aguirre escribía en enero de 2008 un demoledor artículo, titulado La gran estafa de la Filología Clásica, en el que se quejaba del inmovilismo en nuestras materias:

Mi primera idea al verme profesor de griego -y latín debido a que en la mayoría de centros basta con un profesor para impartir ambas materias- fue el buscar métodos para poder impartir las lenguas clásicas como si fuesen modernas. Para mi desesperación no había nada; ni siquiera existía una bibliografía mínima sobre el tema. La filología clásica se había quedado obsoleta, y así no era de extrañar que nuestras disciplinas cada vez estuviesen más arrinconadas y casi al borde de la desaparición: todos los estudios de los filólogos más importantes desde Chomsky que tienen como fruto la renovación de los métodos didácticos de lenguas extranjeras, son ignorados por los filólogos clásicos. La filología clásica parece vivir de espaldas a los principales avances de la lingüística general.

La lingüística general actual ha apostado de forma científica e indudable por el enfoque comunicativo como el mejor y más productivo método de la enseñanza de las lenguas y, sin embargo, en el mundo de la filología clásica esto es absolutamente ignorado. Cuando en filología clásica se habla de "métodos modernos" en lo que se piensa es en aplicaciones informáticas con paradigmas que hay que rellenar en el ordenador o análisis sintácticos realizados con ayuda de un retroproyector. [...] Una pena que los que presumíamos de ser la vanguardia y la élite de los estudios filológicos nos hayamos quedado casi un siglo atrás de nuestros colegas de las filologías modernas.

De igual manera, Santiago Carbonell (2010: 85) escribía lo siguiente:

La cuestión del método está hoy más viva que nunca, habida cuenta del evidente fracaso del sistema tradicional. Cada vez más profesores demandan y crean materiales adaptados a las nuevas realidades sociales. [...] La competencia lingüística, y no el conocimiento pasivo de la teoría gramatical, constituye el único objetivo posible de una didáctica que devuelva a nuestros estudios clásicos su utilidad tan largamente cuestionada. 
En su artículo “Desaprendiendo griego antiguo", publicado en 2012, nos presenta una propuesta didáctica para trabajar con Athenaze en griego y con Familia Romana en latín, partiendo de la siguiente premisa (Carbonell 2012: 229-230):

El estudio teórico de los fenómenos gramaticales y la práctica de traducción de pasajes originales, seleccionados a modo de ejemplo en función de su nivel de dificultad, eran, hasta no hace mucho tiempo, el único modo aparente de aprender lenguas clásicas y de acceder al legado antiguo. Esta didáctica, que ha prevalecido en nuestras aulas más por rutina académica, quizás, que por convicción, empieza a revelarse ya como absolutamente insuficiente para no pocos docentes.

Ante los evidentes resultados de este modelo, se ha despertado hoy un interés creciente por recuperar las bases de la tradición humanística, al tiempo que se ha encontrado en las nuevas tecnologías una nueva vía para un enfoque metodológico basado en el aprendizaje autónomo y la interacción en entornos virtuales colaborativos. A su vez hemos empezado a adaptar a nuestras clases algunas técnicas recientes en la enseñanza-aprendizaje de las lenguas extranjeras, desacralizando para ello los textos clásicos y dando mayor importancia a la creatividad.

[...] En lugar de recurrir a las antologías literarias, muchos solemos ya optar por textos no originales compuestos precisamente para facilitar el aprendizaje de nuestras lenguas. En la didáctica del griego antiguo, como en la del latín, creemos que es válida la idea existente en las filologías modernas y medievales de que es fundamental iniciar a los alumnos en la lectura de los textos de la respectiva tradición literaria a través de adaptaciones graduadas.

Afortunadamente, la "silenciosa revolución", en palabras de un periodista, ${ }^{13}$ del latín ha conseguido que personalidades como Mary Beard, catedrática de la Universidad de Cambridge, considerada la "clasicista más conocida de Gran Bretaña" y que fue galardonada con el premio Princesa de Asturias 2016 "por su sobresaliente contribución al estudio de la cultura, de la política y de la sociedad de la antigüedad grecolatina", ${ }^{14}$ llegara a afirmar en su libro El mundo clásico: una breve introducción, publicado en 1995 (y no traducido al castellano hasta 2016), lo siguiente (Beard y Henderson 2016: 170-1):

Como bien es sabido, los colegios de otra época solían bombardear a los niños de familias ricas con la gramática latina; en los exclusivos internados británicos de hace cien años apenas si se enseñaba más que griego y latín. La idea no era, sin embargo, abrir la puerta a los alumnos a toda una sugerente literatura antigua que pudieran leer con soltura en el original, sino inculcarles los modos de pensamiento lógico que, supuestamente, uno adquiría mediante un atento aprendizaje del conjunto de las reglas gramaticales. [...]

Hoy en día, solo un lunático puede seguir pensando que aprender reglas gramaticales tenga un efecto positivo en el razonamiento lógico de los alumnos, pero sigue siendo objeto de debate cuál ha de ser la forma más adecuada de enseñar las lenguas latina y griega.

${ }^{13}$ Alejandro Zabaleta, "El latín prepara su revancha", publicado el 27/02/2017 en La Provincia: diario de Las Palmas y reproducido en la web <www.culturaclasica.com/?q=node/6445> [consulta: 1 diciembre 2019].

$14<$ <ww.fpa.es/es/premios-princesa-de-asturias/premiados/2016-mary-beard.html?texto=acta> [consulta: 1 diciembre 2019]. 
Esta revolución ha sido en buena medida propiciada por las numerosas actividades organizadas por la Asociación Cultura Clásica que, constituida en nuestro país en junio de 2003, ha dedicado desde el inicio sus esfuerzos, entre otros fines, a la formación del profesorado en nuevas metodologías para la enseñanza del latín y el griego antiguo. Así, desde el año 2005 se han celebrado anualmente sin interrupción las Jornadas de Cultura Clásica, ${ }^{15}$ en las que han tenido lugar diversas mesas redondas en torno a la didáctica del latín y el griego con la participación de representantes de diversas asociaciones de lenguas clásicas, como la SEEC, la SELat, la AALG y la propia Cultura Clásica, y que han contado, además, con la presencia de conferenciantes internacionales como Hans Ørberg, Luigi Miraglia, Michael von Albrecht, Andreas Fricht, Dirk Sacré, Nancy Llewellyn, Cristophe Rico, Eduardo Engelsing, Rüdiger Niehl, Sigrides Albert, Jiř́i Čepelák, Charles Delattre, Bas van Bommel, John Hazel, Roberto Carfagni o Gerardo Guzmán, que han impartido sus ponencias en latín o en griego antiguo.

Además, desde agosto de 2013 se viene celebrando en Madrid el curso anual CÆLVM (Cursus Aestivus Latinitatis Vivae Matritensis), ${ }^{16}$ organizado por la Asociación Cultura Clásica y la Universidad de Málaga, con la colaboración del Collegium Latinitatis ${ }^{17}$ y el apoyo de la SEEC, que ha ido creciendo desde los 65 participantes en su primera edición hasta los 190 que se dieron cita en la de 2019. Como su propio nombre indica, se trata de un curso impartido íntegramente en latín por profesores experimentados en la docencia tanto en Institutos de Secundaria como en la Universidad. Los destinatarios son profesores, alumnos universitarios y personas interesadas en el estudio activo de la lengua latina, que tengan conocimiento previo de los conceptos morfosintácticos fundamentales de la lengua y conozcan el léxico básico latino. El curso consta de 50 horas de clase y los participantes se agrupan en tres niveles de competencia lingüística: Ianua (A1, A2), Atrium (B1, B2) y Palatium (C1). Los objetivos son mejorar la competencia activa en lengua latina de los participantes, profundizar en la lectura y comprensión de los textos latinos y mostrar el mayor número de recursos posibles para enseñar latín en latín.

Por último, y para dar voz al profesorado formado dentro y fuera del CÆLVM, en noviembre de 2018 se celebró en Málaga la primera edición de Novae Viae, ${ }^{18}$ un encuentro anual dirigido a la exposición de experiencias innovadoras en la enseñanza del latín y el griego.

Este deseo de cambio, alentado por tantos profesores en nuestro país, propició que el día 25 de marzo de 2017 se celebrara en Madrid, en la sede de la Sociedad Española de Estudios Clásicos y a petición de sus socios, el Coloquio

\footnotetext{
$15<$ wWw.culturaclasica.com/jornadas $>$ [consulta: 4 diciembre 2019].

$16<$ wWw.culturaclasica.com/caelum $>$ [consulta: 4 diciembre 2019].

$17<$ collegiumlatinitatis.com> [consulta: 4 diciembre 2019].

$18<$ www.culturaclasica.com/novaeviae> [consulta: 4 diciembre 2019].
} 
Métodos de enseñanza del latín y del griego, en el que un nutrido grupo de profesores de Griego y Latín de Enseñanza Secundaria y Universidad se reunió para debatir sobre los objetivos, los métodos y las condiciones legales de la enseñanza del Griego antiguo y el Latín hoy en España. Entre el resultado de las deliberaciones publicadas por la SEEC (VV. AA. 2017: 2) se recoge que:

En último término, la comunidad educativa debe asumir que los métodos activos de enseñanza del Griego y el Latín han alcanzado en España un nivel, una extensión y unos resultados que los convierte en aspectos fundamentales de la renovación didáctica de la enseñanza de tales lenguas. [...] En conclusión, los nuevos métodos de enseñanza del Griego antiguo y el Latín ofrecen un panorama lleno de esperanza e ilusión, pues, como demuestran sus resultados, permiten alcanzar con mucha mayor rapidez y solidez el objetivo final de estas enseñanzas: que los alumnos sean capaces de dominar hasta un cierto nivel las dos lenguas clásicas y, por medio de ellas, obtengan una mejor formación e información sobre el Mundo Clásico, que es la base de nuestra cultura y nuestras lenguas y la de otros muchos países del Mundo.

\section{A MODO DE CONCLUSIÓN}

Al hilo de estas conclusiones, permítaseme de nuevo citar a Mary Beard (Beard y Henderson 2016: 188), convencido como estoy de que hoy, más que nunca, necesitamos personas mediáticas como ella que defiendan con coraje la enseñanza de las lenguas clásicas:

Estudiar el mundo clásico nunca será una actividad inerte, por mucho que se califique de "muertas" a las lenguas antiguas y a las culturas que las hablaron, pues la cultura occidental depende a tal extremo de siglos de exploración del legado del mundo clásico, que este se halla, por así decir, en las raíces mismas de prácticamente cuanto hoy podemos decir, ver o pensar.

\section{BIBLIOGRAFÍA}

AlCALDE-DiOSDADO, A. (2000), “La necesidad de renovación didáctica de las lenguas clásicas: una nueva propuesta metodológica", Estudios Clásicos, 118, 95-131.

BeARD, M. y Henderson, J. (1995), Classics. A very Short Introduction, Oxford, Oxford University Press (trad. de Cuesta Aguirre, M., El mundo clásico: una breve introducción, Madrid, Alianza, 2016).

CANALES, E. y AMADOR, A. G. (2014), “La enseñanza del latín a través del método inductivo-contextual”, en Baetica Renascens, Maestre, J. M. (coord.), vol. II, Cádiz / Málaga, Federación Andaluza de Estudios Clásicos, 1293-1312.

CARBONELL, S. (2010), "La crisis del Griego antiguo y los métodos antidepresivos", Estudios Clásicos, 137, 85-95.

CARbonelL, S. (2012), "Desaprendiendo griego antiguo: una propuesta didáctica para un primer curso con Athenaze", Thamyris, 3, 229-249.

ComeniUs, J. A. (1657), Opera didactica omnia, Ámsterdam, Geer. 
CVC: Diccionario de términos clave de ELE [en línea]. Madrid: Centro Virtual Cervantes, 2019 [consulta: 1 diciembre 2019]. Disponible en: <cvc.cervantes.es/ensenanza/ biblioteca_ele/diccio_ele>.

Debut, J. (1974), L'enseignement des langues anciennes, París, Presses Universitaires de France (trad. de Esteban, I., La enseñanza de las lenguas clásicas, Barcelona, Planeta, 1976).

FORNACIARI, M. (1947), Latinorum: guida pratica per i genitori dei ragazzi che studiano il latino, Milán, Longanesi (trad. de Matons Rossi, C., Latinorum. Guía práctica para los padres cuyos hijos estudian latín, Barcelona, Gustavo Gili, 1952).

JiMÉNEZ DelGADO, J. (1959), “El Latín y su didáctica”, Estudios Clásicos, 28, 153-171.

LATAPí, P. (1993), “El pensamiento educativo de Comenio”, en Juan Amós Comenio: obra, andanzas, atmósferas, Aguirre Lora, G. M. E. (coord.), México, UNAM, 139-158.

LÓPEZ DE LERMA, G. (2015), Análisis comparativo de metodologías para la enseñanza y el aprendizaje de la lengua latina, Barcelona, Universidad de Barcelona [tesis doctoral].

MaCíAS ViLlalobOS, C. (2017), “La aplicación del método inductivo-contextual a la enseñanza del latín a nivel universitario", en O Ensino das Línguas Clássicas: reflexões e experiências didáticas, Cravo, C. y Marques, S. (coords.), Coímbra, Universidade de Coimbra, 13-33.

MARTínez AGuiRre, C. (2008), La gran estafa de la Filología Clásica [en línea]. Disponible en: <www.culturaclasica.com/?q=node/1904> [consulta: 1 diciembre 2019].

MARX, K. (1975 [1835]), “An principatus Augusti merito inter feliciores reipublicae Romanae aetates numeretur?", en Marx/Engels Gesamtausgabe (MEGA), vol. I.1, Berlín, Dietz, 465-469.

MiraGliA, L. (1996), “Come (non) si insegna il latino", Micromega, 5, 217-233 (trad. de Hernández Vizuete, J., “Cómo (no) se enseña el latín” [en línea]. Disponible en: $<$ www.culturaclasica.com/lingualatina/miraglia.htm> [consulta: 1 diciembre 2019]).

MirAgliA, L. (2009), Nova Via. Latine doceo, Montella, Accademia Vivarium Novum (trad. de Canales, E. y Amador, A. G., Nova Via. Latine doceo, Guadix, Cultura Clásica, 2013. Disponible en: <www.culturaclasica.com/lingualatina/profesorado.htm> [consulta: 1 diciembre 2019]).

ØrberG, H. H. (2003 ${ }^{8}$ [1991]), Lingua Latina per se illustrata. Pars I: Familia Romana, Grenaa, Domus Latina (ed. en color: Granada, Cultura Clásica, 2011).

ØRBERG, H. H. (20035 [1990]), Lingua Latina per se illustrata. Pars II: Roma aeterna, Grenaa, Domus Latina (ed. en color: Montella, Accademia Vivarium Novum, 2018).

Paine, W. L., MAINWARING, C. L. y RYLE, E. (1912), Decem fabulae pueris puellisque agendae, Oxford, Clarendon Press.

Ramos Maldonado, S. (2015), "Proyecto Sal Musarum ad iuuenes studiosos collatus: una adaptación moderna de los métodos de los humanistas para la enseñanza de la lengua latina", Thamyris, 6, 167-200.

RAMOS MALDONADO, S. (2016), "Sal Musarum: La vía de los humanistas en la enseñanza de la lengua latina (De lingua latina docenda per uiam quae dicitur humanistarum)", Methodos, 3, 1-26.

RigHI, G. (1962), Breve storia della Filologia Classica, Florencia, Sansoni (trad. de García de la Mora, J. M., Historia de la filología clásica, Barcelona, Labor, 1969).

Rouse, W. H. D. y APpleton, R. B. (1925), Latin on the direct method, Londres, University of London Press. 
STROH, W. (2007), Latein ist tot, es lebe Latein! Kleine Geschichte einer grossen Sprache, Berlín, List (trad. de Fernández, F., El latín ha muerto, jviva el latín! Breve historia de una gran lengua, Barcelona, Subsuelo, 2012).

TÁRREGA GARRIDO, J. (2018), "Fluvii transitum ponte coniungamus. De auctoribus in lyceis per usum tractandis", Thamyris, 9, 139-154.

Torrent, F. (1976), Latín. Segundo curso de B.U.P., Madrid, Sociedad Española de Estudios Clásicos / G. del Toro.

VV. AA. (2017), Sobre la enseñanza del Griego antiguo y el Latín en España hoy: fines, métodos, marco (Manifiesto de Madrid 2017. SEEC) [en línea]. Madrid: SEEC, 30 marzo 2017 [consulta: 1 diciembre 2019]. Disponible en: <www.estudiosclasicos.org/wpcontent/uploads/3-Conclusiones-Manifiesto-de-Madrid-2017_-SEEC.pdf>. 